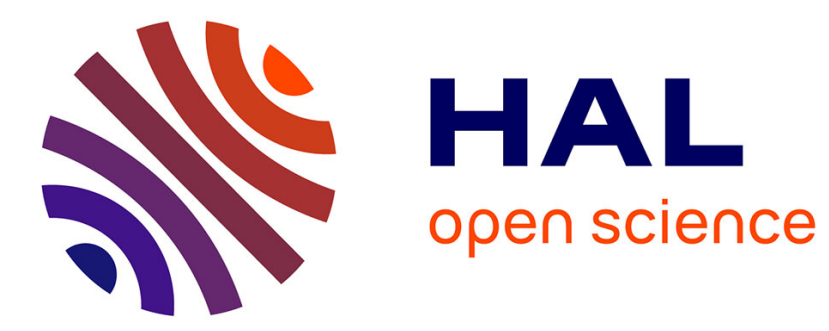

\title{
Design and acceptability assessment of a new reversible orthosis
}

\author{
Nathanaël Jarrassé, J. Robertson, Philippe Garrec, Viviane Pasqui, Yann \\ Perrot, Agnès Roby-Brami, D. Wang, Guillaume Morel
}

\section{To cite this version:}

Nathanaël Jarrassé, J. Robertson, Philippe Garrec, Viviane Pasqui, Yann Perrot, et al.. Design and acceptability assessment of a new reversible orthosis. International Conference on Intelligent Robots and Systems, IEEE, Sep 2008, Nice, France. pp.1933-1939, 10.1109/IROS.2008.4651014 . cea-01175507

\section{HAL Id: cea-01175507 https://hal-cea.archives-ouvertes.fr/cea-01175507}

Submitted on 10 Jul 2015

HAL is a multi-disciplinary open access archive for the deposit and dissemination of scientific research documents, whether they are published or not. The documents may come from teaching and research institutions in France or abroad, or from public or private research centers.
L'archive ouverte pluridisciplinaire $\mathbf{H A L}$, est destinée au dépôt et à la diffusion de documents scientifiques de niveau recherche, publiés ou non, émanant des établissements d'enseignement et de recherche français ou étrangers, des laboratoires publics ou privés. 


\title{
Design and acceptability assessment of a new reversible orthosis
}

\author{
N. Jarrassé, J. Robertson, P. Garrec, J. Paik, V. Pasqui, Y. Perrot, A. Roby-Brami, D. Wang, G. Morel
}

\begin{abstract}
We present a new device aimed at being used for upper limb rehabilitation. Our main focus was to design a robot capable of working in both the passive mode (i.e. the robot shall be strong enough to generate human-like movements while guiding the weak arm of a patient) and the active mode (i.e. the robot shall be able of following the arm without disturbing human natural motion). This greatly challenges the design, since the system shall be reversible and lightweight while providing human compatible strength, workspace and speed. The solution takes the form of an orthotic structure, which allows control of human arm redundancy contrarily to clinically available upper limb rehabilitation robots. It is equipped with an innovative transmission technology, which provides both high gear ratio and fine reversibility.

In order to evaluate the device and its therapeutic efficacy, we compared several series of pointing movements in healthy subjects wearing and not wearing the orthotic device. In this way, we could assess any disturbing effect on normal movements. Results show that the main movement characteristics (direction, duration, bell shape profile) are preserved.
\end{abstract}

\section{INTRODUCTION}

A physical rehabilitation is not confined to aging-related health problems, butt also to stroke or spinal-cord impairments. Medical rehabilitation usually comprises of physical therapy (PT), occupational therapy (OT), and counseling for emotional support. For PT and OT, intensive manual medical attention from therapists is required because effective treatment is based on intensive physical exercise and positioning practice $([1][2],[3])$ to assist functional recovery [4] .

In the perspective of economics of neurological

Manuscript received February 22, 2008. This work was supported in part by the A.N.R. (Agence Nationale de la Recheche ) with the projet BRAHMA (BioRobotics for Assisting Human Manipulation) PSIROB 2006.

P. Garrec and Y. Perrot are with the CEA,LIST, Service de Robotique Interactive, 18 route du Panorama, BP6, 92265 Fontenay-aux-Roses, France, (phone: 33-1-46-54-89-94, fax: 33-1-46-54-89-80; e-mail: philippe.garrec ; perrot@cea.fr )

N. Jarrassé, G. Morel, J. Paik, V. Pasqui are with the ISIR (Institut des Systèmes Intelligents et de Robotique) ISIR-UPMC (Institut des Systèmes Intelligents et Robotique from Université Pierre et Marie Curie Paris VI). 4 Place Jussieu 75252 Paris Cedex, France.(phone : 33-1-46-54-78-12, fax : 33-1-46-54-72-99 ; e-mail : jarrasse ; morel ; paik ; pasqui@ @isir.fr )

J. Robertson and A. Roby Brami are with the LNP (Laboratory of Neurophysics and Physiology) - Université René Descartes Paris V, 45 rue des Saints Pères, 75270 Paris Cedex 06, France. (phone 33-1-42-86-21-38; fax: $\quad 33-1-49-27-90-62 ; \quad$ email: johanna.robertson agnes.roby-brami@univ-paris5.fr ).

D. Wang is with the Sensorimotricy Platform of Université René Descartes Paris V, 45 rue des Saints Pères, 75270 Paris Cedex 06, France (phone : 33-1-42-86-43-59 ; email : danping.wang@univ-paris5.fr ) rehabilitation, and its limited treatment options in duration, sophisticated rehabilitation robotic systems can only be of benefit to the medical society and the patients: it can provide effective means of treatment with high functionality, personalization, repeatability, and force scalability.

Amid the growing medical robot industries, there have been quite a few product and research developments in robots specific to upper-limb rehabilitation (see [5]), following the pioneer MIT-Manus [6]. This system has a $2 \mathrm{DoF}$ manipulator that exerts forceson the patient's hand through a handle. It thus can provide assistance only at the end-point level, failing to address the crucial problem of assisting the internal motion of the redundant human arm.

This is why an upper-limb orthoses, that patients wear on the whole arm to practice therapeutic exercises, have been more recently investigated. Our work fits in this research area. The technical challenge lies in mechanically enabling total degrees of freedom in the arm while respecting its biomechanics (speed, torque, center of rotation, workspace, etc.), an adequate control bandwidth and algorithm for a transparent human robot interaction, an inherent safety (compliant joints and applied joint torque monitoring), a comfortable physical interface with the patient are just few design criteria for developing a robotic orthosis for comprehensive therapy.

Kiguchi and Fukuda's 3 DoF exoskeleton [4] is developed to assist physical therapy and has safe compliant joints as it is driven by cables from DC motor connections. However, it has a low control frequency due to the naturally unstable EMG signal and a limited range motion designed for minimal task executions just under shoulder height. For a wider range of motion, Haptic arm exoskeleton, MAHI ([7],[8]) has a unique parallel link structure for eliminating singularities and maximizing its workspace which approximately matches that of the human (so does RUPERT, [9]). However, with a price of having either restrictive encasing ([7],[8]) or limited DoF around the shoulder ([7], [8],[9]) reducing its applicability in total upper limb rehabilitation. L-EXOS [10] has $70 \%$ of human workspace with sufficient shoulder DoF but with a higher weight and customized parts. With a full 9 DoF [11], 9 DoF passive skeleton device replicates comprehensive DoF of human body and range of motion with its light weight, however, this passive architecture is unsuitable for robot assisted physiotherapy. A portable exoskeleton from KIST [12] has a full 7 DoF for realizing human arm movements. It was designed to idealize human-robot interaction and consequent motion teaching rather than therapeutic usage; therefore, its applicability in rehabilitation usage for guiding patient arms is questionable regarding its actuation 
capabilities.

ARMin I and II [13],[14], WREX [15] and CADEN-7 [16] device supports a human arm by having adaptable DoF and range of motion, torque; but their large volume is only suitable for spatious clinical areas.

This paper presents a new design of a portable and reversible cable transmission orthosis, ABLE, that was designed to have a maximum therapeutic effectiveness. This translates into a mechanical design with a minimum backlash and friction actuator, together with a low level control algorithm for a fluid and transparent human robot interaction, all while being safe and comfortable for medical practices. The detailed mechanical design, characteristics and kinematics of the orthosis are covered in Section 2. The experimental setup and procedures used to test robot with healthy subjects are illustrated and explained in Section 3. Section 4 reports the results of the experiment that confirms the validity of the device applicability, through preliminary tests that compared the movements of healthy subjects performing pointing tasks with and without wearing the orthosis programmed to be in a transparent mode.

\section{MECHANICAL DESIGN}

\section{A. General orthosis kinematics}

The 4 axes exoskeleton developed for physical rehabilitation is named ABLE (see Fig. 1) by the authors of CEA-LIST. It uses an innovative actuation technology using cable force transmission. ([17],[18],[19][20],[21]).
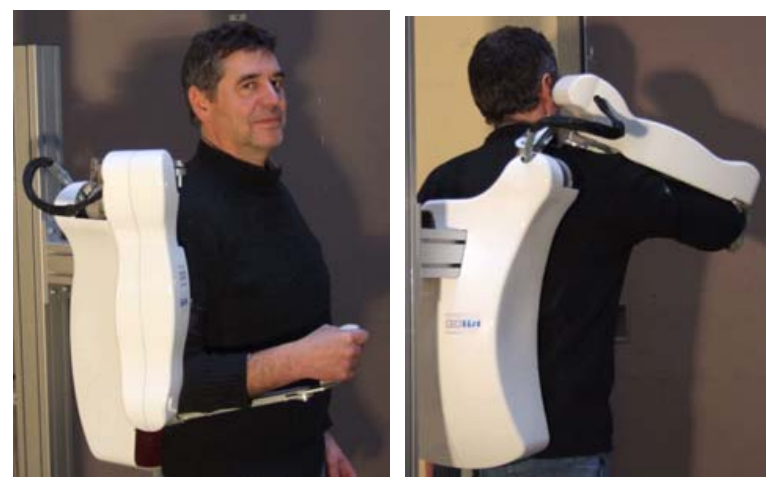

Fig 1. ABLE 4 axis exoskeleton actuated by screw-and-cable actuators

Its kinematics are composed of a shoulder spherical arrangement made with 3 coincident axes and an elbow. The forearm, terminated by a handle, is not actuated. Its kinematics are sketched in Fig. 2, and the Dennavit \& Hartenberg parameters are shown in Table 1.
4 ddl exoskeleton kinematics

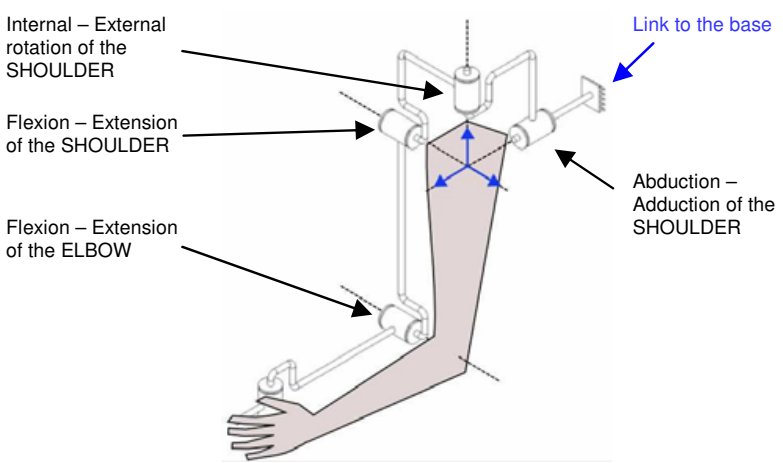

Fig 2: Kinematics of ABLE

\begin{tabular}{|c|c|c|c|c|}
\hline$i$ & $\alpha_{i}$ & $a_{i}$ & $\theta_{i+1}$ & $d_{i+1}$ \\
\hline 0 & $-\pi / 2$ & 0 & $\Theta_{1}$ & 0 \\
\hline 1 & $-\pi / 2$ & 0 & $\Theta_{2}$ & 0 \\
\hline 2 & $\pi / 2$ & 0 & $\Theta_{3}$ & 0 \\
\hline 3 & $-\pi / 2$ & 0 & $\Theta_{4}$ & $\mathrm{~d}_{1}$ \\
\hline
\end{tabular}

Table 1: DH paramaters of ABLE

\section{B. Transmission - Actuators}

Most of the technological originality of ABLE comes from its actuation and transmission system, which is based on a CEA-patented Screw-and-Cable System (SCS) [22].

The SCS actuator design principle is as follows (see Fig 3): a hollow screw is locked in rotation - the nut rotating in a bearing - and translates without being guided linearly. The locking device - a simple pair of rollers moving inside a slot is coupled to the screw by a flexible coupling in order to absorb beating oscillations resulting from the lack of linear guiding. A transmission cable is attached in the middle. Due to the radial backlash between the cable and the bore of the screw, beating oscillations are not counteracted and the misalignment of the cable has virtually no influence on the bending moment of the screw. The result is a regular and a very low friction threshold and the efficiency of the screw is neither affected by any geometrical defaults nor by the eventual deformation of the structure under load.

The overall advantages of the SCS transmission are:

- A high force capacity, thanks to a high overall gear ratio;

- A low friction threshold and high backdrivability;

- An alignment of the motor parallel to cable, which permits highly compact arrangement as compared to transversal motors or beveled gearboxes;

- A low inertia and high stiffness;

- A high tolerance to manufacturing incertitude and to structure flexibility, which allows a wide choice of structural material.

The SCS also benefit from inherent advantages of the cable transmissions, which are shock absorption capabilities, smoothness, high efficiency, versatility (efficient angle transmission, intricate routings through joints). 


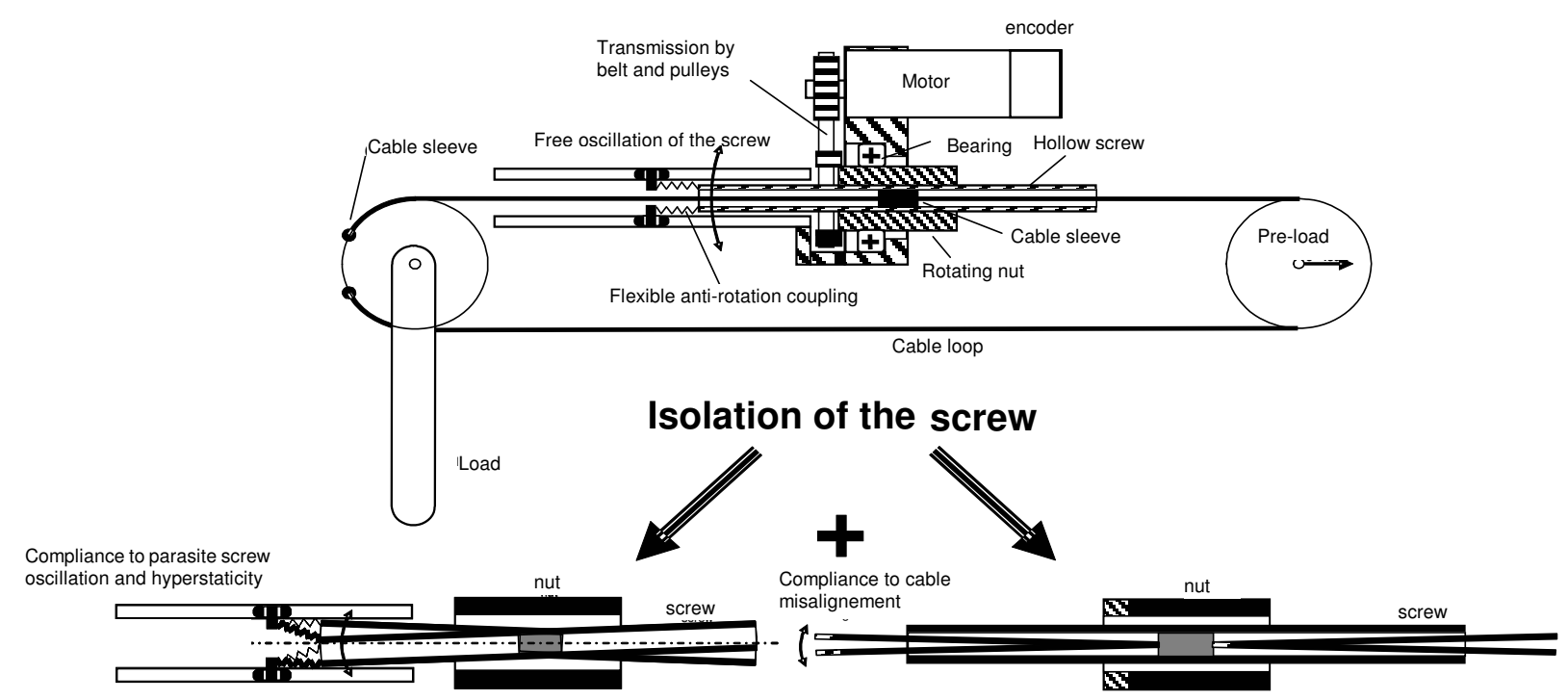

Fig 3. Basic principle of a SCS

An important capabilitie is the tolerance to vibrations of the rotating parts like, the screw, as much as cable misalignements, thanks to a minimized cable fixation area and flexible couplings placed between screw and cable guidance parts (See Fig. 3).Details on the designs and features of the SCS can be found in [19], [21].

In the ABLE exoskeleton, the SCS are partially embedded in limb very much alike electrical muscles, as illustrated in Fig. 4.
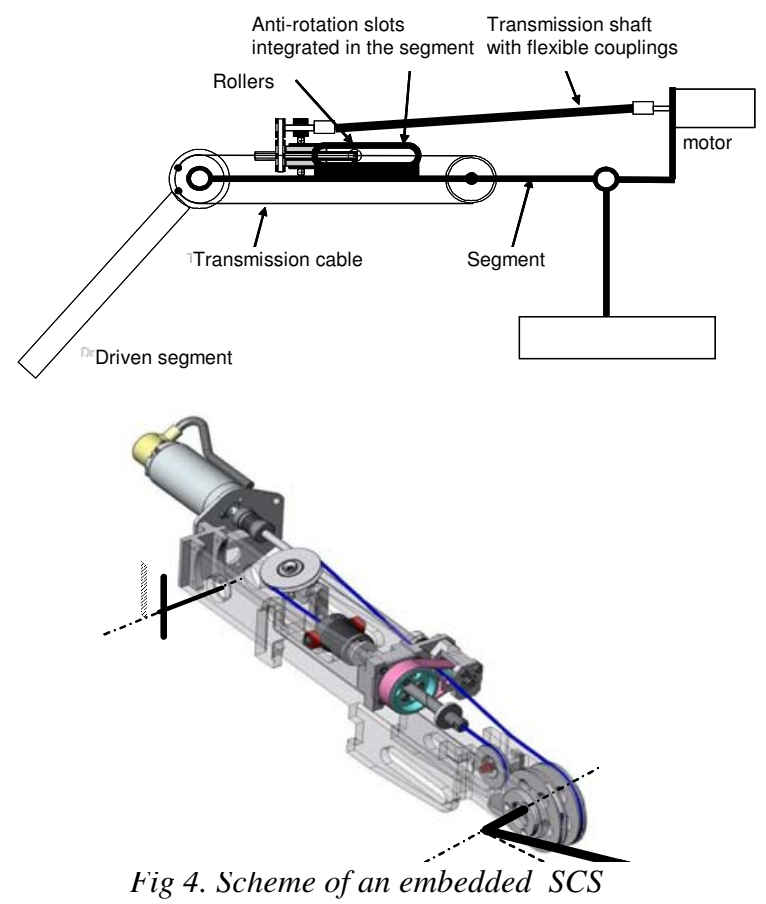

The integration of the cable loop inside the limb shortens the cable and increases the transmission stiffness, whereas the location of the motors close to the joint axis drastically decreases the inertial effect of embedded motor masses, resulting in a satisfactory tradeoff.

Each of the back and arm modules integrates two SCS. The overall mass/volume of the mechanics is then spread along the structure allowing to closely follow the human morphology and achieve a better balance.

Figure 5 shows ABLE's transmission kinematics. The back module drives the two first axis of the shoulder (Joint 1 and 2). The arm module drives two transversal axis (Joint 3 and 4). Joint 3 is the third axis of the shoulder making it an equivalent of a spherical articulation, while Joint 4 is the elbow axis.
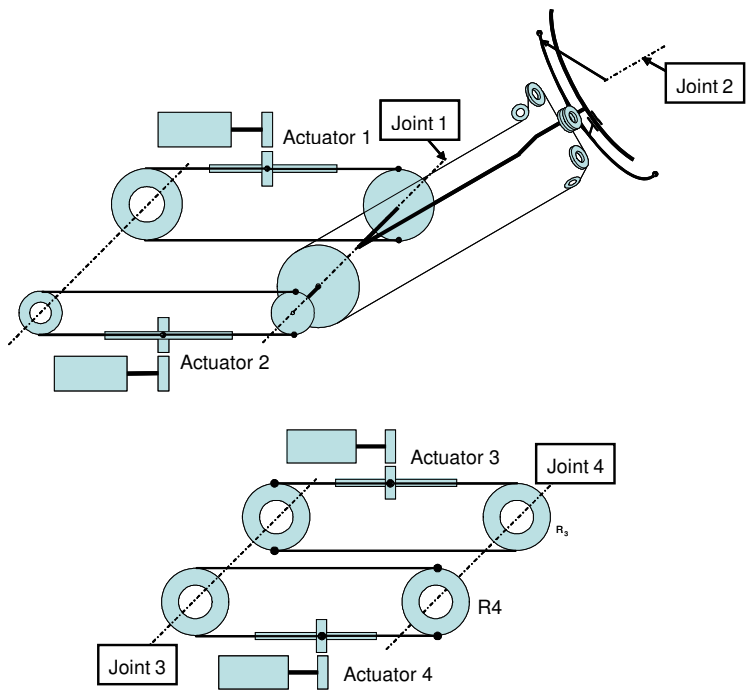

Fig 5. Back module transmission and shoulder (top) Arm module transmission (bottom)

The shoulder design is kept simple and discrete. It is made of a part that articulates on the back (Joint 1) and also 
supports a circular guide which defines a second virtual axis perpendicular to the first (Joint 2). Their intersection defines the virtual center of the exoskeleton spherical.

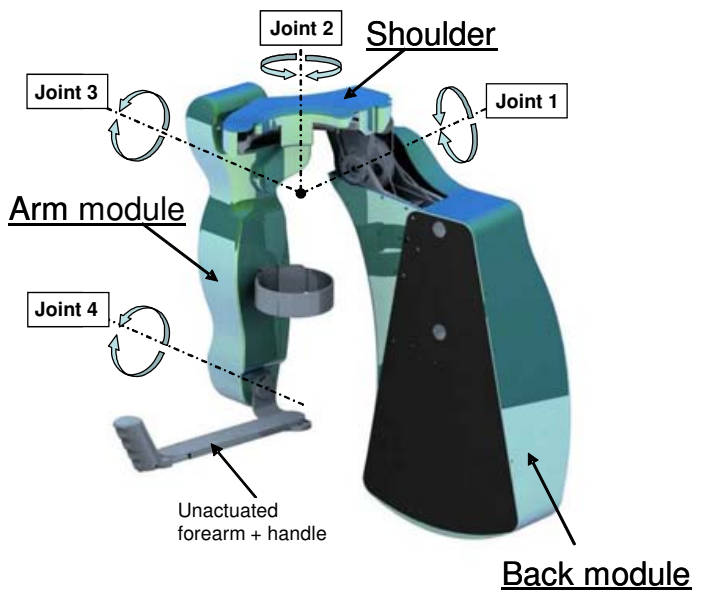

Fig 6. General view of $A B L E$

It is important to note that the back module may receive the motorization of the second exoskeleton without increasing in volume.

The arm mass with the motors is $2,3 \mathrm{~kg}$. The table 2 below summarizes the other basic mechanical specifications of ABLE.

\begin{tabular}{|c|c|c|c|c|}
\hline \multirow{2}{*}{ JolNT } & Axis 1 & Axis 2 & Axis 3 & Axis 4 \\
\cline { 2 - 5 } & Abduction / Adduction & Rotation Internal / External & Flexion / Extension & Flexion / Extension \\
\cline { 2 - 5 } & \multicolumn{4}{|c|}{ SHOULDER } \\
\hline Amplitude & \multicolumn{4}{|c|}{$110^{\circ}$} \\
\hline Motors & \multicolumn{4}{|c|}{ DC Faulhaber type } \\
\hline Transmission & \multicolumn{4}{|c|}{ Ball-screw and cable (SCS) } \\
\hline Speed (cartesian) & \multicolumn{4}{|c|}{$>1 \mathrm{~m} / \mathrm{s}$} \\
\hline $\begin{array}{c}\text { Joint torque } \\
\text { (continuous) } \\
\text { hand effort in }\end{array}$ & $18 \mathrm{Nm}$ & $18 \mathrm{Nm}$ & $13 \mathrm{Nm}$ & $13 \mathrm{Nm}$ \\
\hline $\begin{array}{c}\text { Contion } \\
\text { ho-load friction in } \\
\text { hand (approx.) }\end{array}$ & $50 \mathrm{~N}$ & $50 \mathrm{~N}$ & $40 \mathrm{~N}$ & $40 \mathrm{~N}$ \\
\hline
\end{tabular}

Table 2: ABLE basic specifications

\section{EVALUATION OF A TRANSPARENT CONTROLLER FOR MAN-ORTHESIS INTERACTION}

For intricate and specific human robot interaction requirements imposed by medical applications, the hardware characteristics of ABLE serve as an excellent platform for the physical rehabilitation therapies. Its low joint stiffness and naturally compliant joints ensure the safety while using the robot for patients with physical disability. As a part of the BRAHMA project, the authors have built the hardware, applied control schemes with a high transparency, and had human subjects to try the device. In this section, the focus of the experiment, the control architecture for running the tests, and methods and procedures for evaluating the robot performance and its efficacy on volunteer subjects are described.

\section{A. Aim}

The overall aim of the BRAHMA project is to design and control a robotic orthosis suitable for rehabilitation of the hemiparetic upper limb. Prior to beginning testing on patients, it was imperative to assess the influence of the robot on arm movement in healthy subjects first.

The aim of the experiment was twofold. The first aim was to evaluate the transparency of the robotic-orthosis. If it is totally transparent, kinematic parameters during pointing movements should not be different from kinematic parameters during the same pointing movements without the orthosis. The parameters evaluated to determine this were peak hand tangential velocity, the number of peaks in the hand velocity curve (indication of smoothness [22] ) and curvature of hand path (namely the ratio of the total length of the trajectory on the $3 \mathrm{D}$ distance between the beginning and end of the movement). The second aim was to assess if the subject's arm moved within the orthosis during movements to different parts of the workspace. To ascertain this information, the difference in distance between two adjacent markers near the elbow (one on the orthosis, the other on the subject) was calculated at the start and end positions for each target.

\section{B. Controller}

The torque of the motor is in general, a combination of gravity compensation torque (computed) and a reaction torque computed from an position error signal, the difference between the awaited position and the measured position (PID controller). Therefore a position error denotes an output force exerted either by the operator or by a contact with an object. In quasi-static situations, the proportionality between the position error and the exerted force is directly dependant upon the amount of friction in the transmission as shown on Fig 7. In absence of contact/reaction force the system can be moved under a residual effort given by the distance between the red/blue point and the black point along the $y$ axis. This principle allows us to get a reasonably backdrivable system while using only joint position sensors. More explanations about the controller can be found in [17].

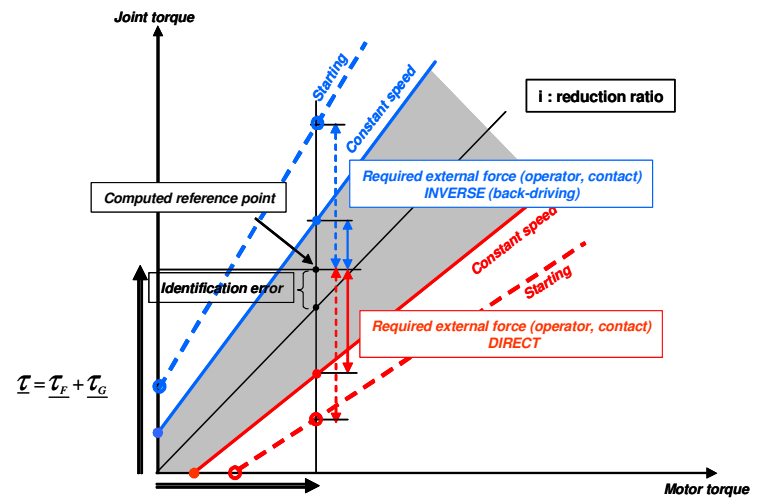

Fig 7. Input-Output force transmission diagram 
The robot controller architecture for the experiments is based on a PC104 board with two endowed 3 channel axis controller. It runs at $1 \mathrm{kHz}$ the control law thanks to a real time operating system (RTlinux).

As the orthotic device is only fitted with optical encoders, we do not have access to an acceleration signal. For those preliminary experiments mainly focused on the mechanical evaluations, only simple compensations were used to achieve transparency. No trajectory were sent to the controller and transparency was achieved thanks to a gravity compensation for all axis and also a compensation for the residual dynamic dry friction compensation for two axis of the shoulder (the ones for shoudler rotation and abd/adduction which have the greatest reduction ratio see Fig. 5). This residual friction compensation has been developped in order to blend the friction phenomenons on all axis, and so on not to lead subject to do non-natural moves because of feelings differences on every joints.

\section{Methods}

Motion tracking was carried out using 2 Codamotion units. The Codamotion system consists of active LED markers each with an individual emitting frequency. Their 3D displacement is captured by wide-angle sensors. 5 infra-red-LED markers were positioned on the orthosis and seven on the subject's upper limb (Fig 8.a). Note that the usual anatomical points could not be used because many were hidden by the orthosis. Biometric data were measured for each subject for further dynamical analysis. Acquisition frequency was $100 \mathrm{~Hz}$.

Nine targets were positioned such in a way as to evaluate movements in different parts of the subject-robot workspace. Target position was determined for each subject by placing the targets so that the shoulder was flexed at $80^{\circ}$ and the elbow flexed at $15^{\circ}$ for the high targets.
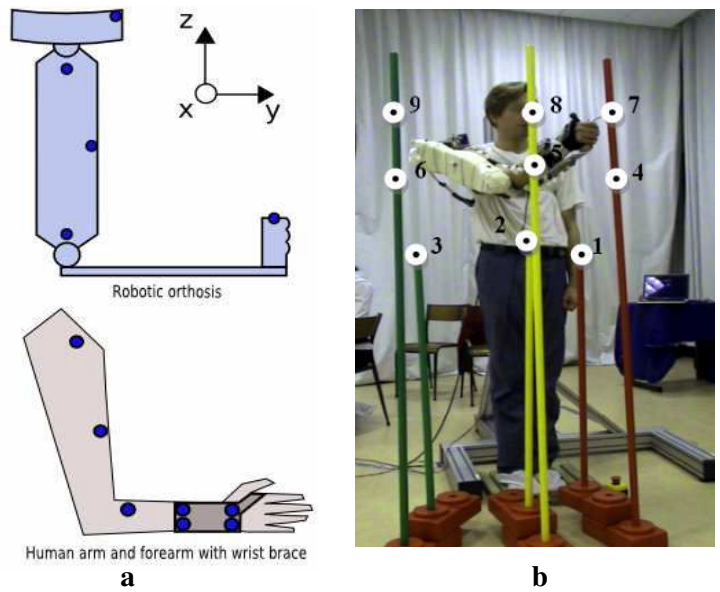

Figure 8. a. Position of Codamotion markers on orthosis and subject; b. Subject pointing to target 7 wearing orthosis. Positions of all targets shown. with the subject's shoulder and $30^{\circ}$ to the left and right (Fig $8 b)$.

The height of the orthosis on its column was adjusted for each subject so that the humeral head was aligned with the axis of shoulder rotation of the orthosis. Subjects wore a wrist brace since wrist movement was not possible while wearing the orthosis, we also wished to prevent wrist movements in the free condition. The trunk was also fixed

\section{Subjects}

At present the segment lengths of the orthosis are fixed and is designed for a tall person. As such, only tall males were recruited. 5 healthy subjects of height $1.82 \mathrm{~m}-1.98 \mathrm{~m}$ aged between 25 and 30 years, naïve to the project agreed to participate.

\section{E. Task}

Subjects were asked to make three consecutive movements to each target (the target order was pseudo-randomised), at natural speed when wearing and not wearing the orthosis. Recordings were also made of a single out and back movement with the robot at maximum subject speed ("rapid with orthosis" curves) to evaluate the impact of inertia phenomenons on human arm trajectory. All movements with and without the orthosis were carried out with the subject in the same initial position.

\section{RESULTS AND DISCUSSION}

As expected, the peak movement velocity varied according to the target distance and position (Fig 9). The average velocity of self-paced movements was $1.3 \pm 0.5 \mathrm{~m} / \mathrm{s}$ in the free condition and significantly decreased to $0.9 \pm 0.3$ $\mathrm{m} / \mathrm{s}$ while wearing the orthosis $(\mathrm{p}<0.0001)$. Fast movements carried out with the orthosis $(1.6 \pm 0.3 \mathrm{~m} / \mathrm{s})$ were only slightly faster than self-paced free movements. This indicates that the robotic-orthosis restricts movement velocity.

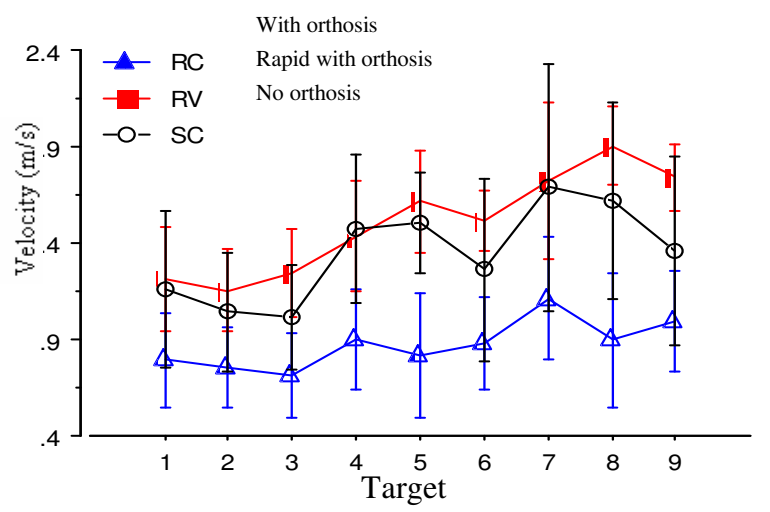

Figure 9. Average peak velocity (and SD) to each target according to condition. 
Normal voluntary 3D reaching movements are characterized by a bell shaped velocity curve with a single peak [24]. The velocity curves for movements while wearing the orthosis had significantly more peaks suggesting a loss of smoothness $(1.7 \pm 0.8$ peaks without orthosis, $3.5 \pm 1.9$ with orthosis $(\mathrm{p}<0.0001))$. The fast movements while wearing the orthosis; however, had less peaks than the self-paced movements with the orthosis $(2.3 \pm 1.0)$.

Natural pointing movement trajectories are often slightly curved. This is indicated by a curvature ratio of the tangential displacement which is greater than 1 in the free condition (1.07 \pm 0.05$)$. This ratio varied with the target and its average increased significantly while wearing the orthosis (1.13 \pm 0.1$)$; however, the effect of wearing the orthosis varied with the position of the target (Fig 10).

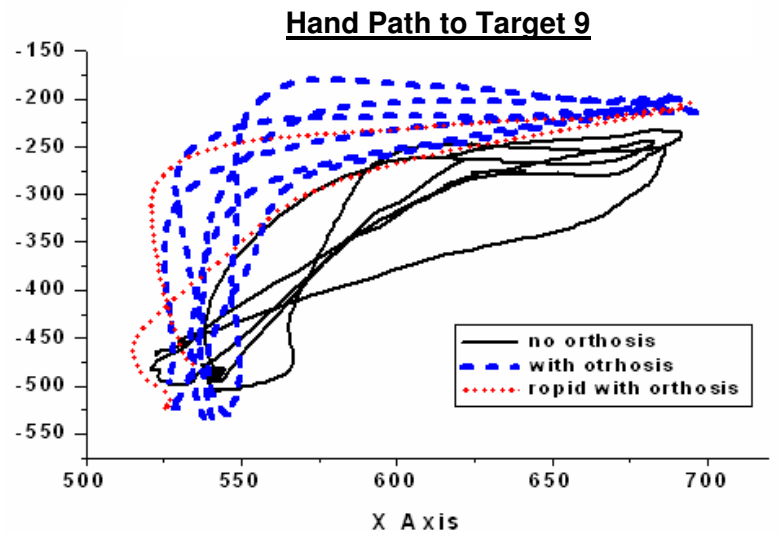

Figure 10. Hand paths viewed from above to one target (the target 9 which is high and external). The orthosis modifies the trajectory dependant on direction.

For the same movement toward the target, the velocity curves show some segmentation compared to the free-state's ideal curve, which would be in a smooth bell shape (Fig 11). The curvature of the movement to external-high target was significantly higher with the orthosis while it was decreased for a forward-middle target. This demonstrates that the orthosis imposed some mechanical constraints on the movement.

However, the effect of increasing movement velocity (average curve ratio $1.12 \pm 0.08$ ) was not clear, suggesting that the deformation of the trajectory was not only due to inertial constraints.

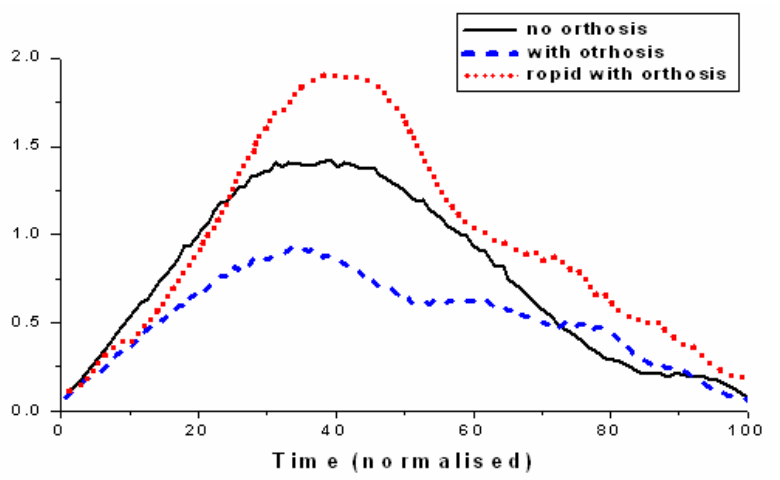

Figure 11. Velocity curves for movements to target 9 for one subject in the three conditions.

Movement of the subjects' arms relative to the orthosis was ascertained by the difference in tangential distance of the marker on the subject's lower humerus to the adjacent marker on the orthosis. There was an average movement of $3.1 \mathrm{~cm} \pm 1.9$. This movement was generally greater for higher targets.

\section{CONCLUSION}

The developed orthosis, ABLE, received positive feedback from the participating subjects who were able to make a wide range of movements in $3 \mathrm{D}$. However, it induced some clear alteration in self-paced motion trajectories: meaning that the transparency of the ABLE during the general slowing and modification of trajectory is still limited. Further analysis of exact physical effects in joint and actuator rotations are needed to determine the mechanism of these effects: role of inertial and viscous constraints, effect on the synchronisation of the robotic and human joints rotations.

One of the main application of an exoskeleton is for physical rehabilitation where it can control the movement of each segment. Therefore, the movement of the robot, ABLE, can produce movements closer to that of the human. The ABLE will be used to rehabilitate normal inter-joint synergies that are impaired in hemiparetic stroke patients and discourage pathological synergies[25],[26].

Our future work is now focused on two points. One is to improve control transparency (more transparent control scheme can be used for patients who has made a large recovery in the movements in order not to badly impact patient moves which do not need robot assistance). We are currently working on improving the transparency by predictions from the movement invariants. And another point is to have a larger patient test consensus (especially the test cases when the ABLE is active and drives the arm of a patient for therapy). It is also essential to have a more comfortable and robust physical interface in between the robot and the user. By keeping the isostaticity in this 
interface, we expect to minimize any apparent constraint application on the human arm. For this, the benefits of adding the fifth DoF (the wrist prono-supination) will be evaluated in the following research.

\section{ACKNOWLEDGMENT}

This work is supported by the national research agency ANR PSIROB 2006, through the BRAHMA project (ANR-06-ROBO-0003)

\section{REFERENCES}

[1] Reinkensmeyer, P. Lum, and J.M. Winters, «Emerging Technologies for improving accessto movement therapy following enurologic injury" in Emerging and accessible telecommunications, information and health technologies. Arlington

[2] Asanuma H, Keller A. "Neurological basis of motor learning and memory". Concepts Neuroscience 1991; 2:1-30.

[3] Hesse Stefan, Uhlenbrock Dietmar "A mechanized gait trainer for restoration of gait" in Journal of rehabilitation research and development (J. rehabil. res. dev.) 2000, vol. 37, no6, pp. 701-708

[4] Kiguchi K, Fukuda T "A 3DOF Exoskeleton for Upper-Limb Motion Assist-Consideration of the Effect of Bi-Articular Muscles" in IEEE Int Conf ON ROBOTICS AND AUTOMATION 2004 p.2424-2429d.

[5] Robertson, J., Jarrassé, N., Pasqui, V. and Roby-Brami, A. "Utilisation de robots en rééducation: intérêt et perspectives ", 2007, in Lettre de Médecine Physique et Réadaptation, $n^{\circ} 23$.

[6] Krebs, H.I. and Hogan, N. and Aisen, M.L. and Volpe, B.T. "Robot-Aided Neurorehabilitation" in IEEE transactions on rehabilitation engineering, 1998, March. Vol.6.

[7] Alan Sledd Marcia K. O'Malley, "Performance Enhancement of a Haptic Arm Exoskeleton" Symposium on Haptic Interfaces for Virtual Environment and Teleoperator Systems (HAPTICS'06) p. 58

[8] Abhishek Gupta, and Marcia K. O'Malley, "Design of a Haptic Arm Exoskeleton for Training and Rehabilitation" in IEEE/ASME Transactions on mechatronics, vol.11, no. 3, JUNE 2006 p280-289.

[9] Sugar, T.G. Jiping He Koeneman, E.J. Koeneman, J.B. Herman, R. Huang, H. Schultz, R.S. Herring, D.E. Wanberg, J. Balasubramanian, S. Swenson, P. Ward, J.A. "Design and Control of RUPERT: A Device for Robotic Upper Extremity Repetitive Therapy" in IEEE Transactions on Neural Systems and Rehabilitation Engineering, Sept. 2007 Vol15, Issue3, p.336-346.

[10] Montagner, Alberto Frisoli, Antonio Borelli, Luigi Procopio, Caterina Bergamasco, Massimo Carboncini, Maria C. Rossi, Bruno, "A pilot clinical study on robotic assisted rehabilitation in VR with an arm exoskeleton device", in Virtual Rehabilitation, 27-29 Sept. 2007, p57-64.

[11] Schiele, A. van der Helm, F. C. T "Kinematic Design to Improve Ergonomics in Human Machine Interaction" Neural Systems and Rehabilitation Engineering, IEEE Transactions on. Dec. 2006 Vol14, Issue:4, p456-469.

[12] Yoon Sang Kim Lee, J. Sooyong Lee, "Munsang Kim A force reflected exoskeleton-type masterarm for human-robot interaction",in IEEE Trans. on Systems, Man and Cybernetics, March 2005 Vol. 35, Issue: 2, p198- 212.

[13] Mihelj, M. Nef, T. Riener, R., "ARMin - Toward a six DoF upper limb rehabilitation robot" IEEE/RAS-EMBS Int Conf on Biomedical Robotics and Biomechatronics, 2006. BioRob 2006. p1154-1159.

[14] Mihelj, M. Nef, T. Riener, R. "ARMin II - 7 DoF rehabilitation robot: mechanics and kinematics" 2007 IEEE International Conference on Robotics and Automation, Roma, Italy, 10-14 April 2007.p4120-4125.
[15] Sanchez, R.J., Jr. Wolbrecht, E. Smith, R. Liu, J. Rao, S. Cramer, S. Rahman, T. Bobrow, J.E. Reinkensmeyer, D.J.,"A pneumatic robot for re-training arm movement after stroke: rationale and mechanical design" Int Conf on Rehabilitation Robotics, 2005. ICORR 2005. 9th 28 June-1 July 2005, p500- 504.

[16] Perry, J.C. Rosen, J. Burns, S., "Upper-Limb Powered Exoskeleton Design" in IEEE trans. on Mechatronics, Aug. 2007, Vol12, Issue:4, p408-417.

[17] P. Garrec, J.P. Martins, F. Gravez, Y. Perrot, Y. Méasson "A New Force-Feedback, Morphologically Inspired Portable Exoskeleton" Proceedings of 15th IEEE International Symposium on Robot and Human Interactive Communication (RO-MAN - 2006), September 2006, Hatfield, UK.

[18] Garrec P., Martins J.P., Gravez F., Measson Y.,Perrot Y. ; Une Nouvelle Orthèse Portable à Retour d'Effort Inspirée par la Morphologie ; Handicap 2006, Paris June 2006, France.

[19] Garrec. P, Martins J.P, Friconneau, "A new Technology for Portable Exoskeletons", AMSE 2004 - Vol. 65 n 7/8, pp 13-22.

[20] Garrec. P, Martins J.P, Friconneau, "Une nouvelle technologie d'orthèse portable", Proceedings of Handicap 2004, pp 170-175 Paris, France, juin 2004.

[21] Garrec. P, Friconneau J.P, Louveau F., "Virtuose 6D : a new force-control master arm using innovative ball-screw actuators ", Proceedings of ISR2004 - 35th Symposium on Robotics, Paris, France, mars 2004.

[22] Garrec P., French Patent: «Transmission à vis, écrou et câble attaché à la vis » - FR0101630, 2000 (EUR 01938347.0-2421 and US 10/296,740 (Screw and nut transmission and cable)

[23] Rohrer, B., S. Fasoli, et al. "Movement smoothness changes during stroke recovery." Journal of Neuroscience, 2002, Vol 22, Issue 18, p 8297-304.

[24] Atkeson, C. G. and J. M. Hollerbach. "Kinematic features of unrestrained vertical arm movements." Journal of Neuroscience, 1985, Vol 5, Issue 9, p2318-30.

[25] Levin, M. F.. "Interjoint coordination during pointing movements is disrupted in spastic hemiparesis." Brain, 1996, Vol 119, p281-293.

[26] Roby-Brami, A., Fuchs, S., Mokhtari, M., and Bussel.B. "Reaching and grasping strategies in hemiparetic patients." Motor Control, 1997, Vol 1, p72-91. 